\title{
Chapter 6 \\ Utilisation and Design of Kindergarten Outdoor Space and the Outdoor Activities: A Case Study of Kindergartens in Bergen, Norway and Anji in China
}

\author{
Wanqiu Meng and Min He
}

\begin{abstract}
Compared with Norwegian kindergartens that emphasize how outdoor activity benefits young children's integrated development, Chinese kindergartens reluctantly encourage children to go outside for long time. A county named Anji in South China's Zhejiang province has started to change this approach to outdoor play. Kindergartens there provide outdoor equipment to support children's outdoor activities for longer periods of time. This approach is called Anji Play and has been recommended by Chinese Ministry of Education for all of the country. It has also attracted ECE experts overseas. In this chapter, we describe and analyse children's outdoor play in an Anji setting and in a Norwegian kindergarten from the perspective of the utilisation and design of kindergarten outdoor space. The study takes an ethnographic approach. We collected photo observations, anecdotal recording and interviews from one kindergarten in Bergen, Norway and one in Anji, China. The observation results focusing on outdoor play in the two kindergartens were discussed with kindergarten teachers, principals, professors and college students from China and Norway. Our aim was to interpret the core concepts, goals and concerns of Norwegian and Anji play from multiple perspectives to understand children's cultural formation in the two cultural contexts. We found the cultural values and traditions influence how outdoor play is performed and there are clear links between culture and children's cultural formation.
\end{abstract}

Keywords Kindergarten $\cdot$ Outdoor space $\cdot$ Outdoor play $\cdot$ Norway $\cdot$ Anji $\cdot$ Cultural formation

The original version of this chapter was revised: Acknowledgement has been included at the end of the chapter. The correction to this chapter is available at https://doi.org/10.1007/978-3-03072595-2_12

W. Meng $(\bowtie)$

Preschool Education Faculty, Shanghai Normal University TIANHUA College, Shanghai, China

M. He

Early Childhood Education Department, East China Normal University, Shanghai, China

e-mail: mhe@pie.ecnu.edu.cn

L. T. Grindheim et al. (eds.), Outdoor Learning and Play,

International Perspectives on Early Childhood Education and Development 34,

https://doi.org/10.1007/978-3-030-72595-2_6 


\subsection{Introduction}

The outdoors can be described as an open and constantly changing environment, where it is possible to experience freedom, engage in gross motor development through boisterous movements, and be in contact with natural elements (Maynard $\&$ Waters, 2007). Compared with indoor play, children in the outdoors have more autonomy and can enjoy enhanced space, time and self-chosen activities (Bento \& Dias, 2017). A kindergarten should provide children the best quality of education; Mohidin, Ismail, and Ramli (2015) found that this could be achieved only if the designer, as well as policymakers, are aware of the factors that promote a better environment for these children. Especially in city centers, outdoor spaces that children can use must be designed to meet needs for both children's learning and playful activity. In such designs, both natural and artificial elements must be used (Acar, 2014). Furthermore, Sal1, Akyol, and Baran (2014) claimed that there should be endeavors to provide necessary play equipment in playgrounds. Therefore, the design and utilization of outdoor spaces of kindergarten should be taken seriously.

Nordic countries, especially Norway, emphasize outdoor play in kindergartens for its benefits for children in health, cognition, social communication and other development aspects (Wagner \& Einarsdottir, 2006). Norwegian children spend a significant amount of time in kindergarten outdoors, e.g., $70 \%$ in summer and $31 \%$ in winter semester (Moser \& Martinsen, 2010). Compared with Norwegian kindergarten's promotion of outdoor activity for children's integrated development, Chinese kindergartens reluctantly encourage children to go outside for long periods of time. However, Anji County has introduced outdoor equipment devised to support children's outdoor activities for extended periods of time. It is called "Anji Play" and is recommended by Chinese Ministry of Education for all of the country; it has also attracted Early Childhood Education (ECE) experts from overseas. Indeed, some kindergartens in the United States have purchased Anji kindergarten outdoor equipment to trial. As researchers, we had the opportunity to undertake fieldwork in Anji County and in the city of Bergen, in order to consider the similarities and differences within the cultural formation of outdoor activities and use of environment in both places.

This chapter, therefore, aims to surface the similarities and differences on kindergarten's outdoor space utilisation and design between Anji and Bergen, identify significant features of outdoor activities and explore children's cultural formation through outdoor activities in these spaces.

\subsection{The Background}

\subsubsection{Anji and Bergen}

Anji is a county under the jurisdiction of Huzhou City, Zhejiang Province, located in the hinterland of the Yangtze River Delta with the Tianmu Mountain Range in the southwestern part of the county. It is surrounded by mountains on three sides, with 
a depression in the middle and a sprawling basin topography in the northeast. Anji County administers eight towns, three townships and four streets and had a registered population of 466,100 in 2016. Rich in agricultural resources, with a large number of excellent, new, special and agricultural products, such as bamboo shoots, white tea, mountain vegetables, etc., Anji maintains a high social and economic development level.

Bergen is Norway's second largest city and the capital of Hordaland County. It is also the largest city in western Norway with a registered population of 243,000 in 2017. It is situated on the steep fjord line on the west coast of Norway, leaning against the harbor and seven hills. The warm winds of the Gulf Stream contribute to Bergen's reputation as a rainy city.

\subsubsection{Anji Play: The Way to 'True Play'}

Anji Play is a comprehensive approach to early learning developed over the last 18 years by Ms. Cheng Xueqin, Anji County's Superintendent of Public Early Education and is practiced currently in 130 public kindergartens. It has revolutionized traditional Chinese kindergarten provision with its ethos: "Let the play light up the child's life", which Cheng Xueqin and the other Anji educators call "True Play "'. Its formation is based upon Ms. Cheng's observations of what she describes as three eras of play provision in preschools, from 'no play' to 'false play' to 'true play', according to the official website about Anji play².

\section{Before 2000: 'No Play' Era}

Before 2000, the phenomenon of Early Childhood Education "Primary" was quite common, especially in Chinese county towns and rural areas. Early Childhood Education "Primary" refers to the preschool education that neglects the significance of young children's physical and mental development; instead, young children are expected to learn the content of elementary school using the same approaches for the elementary students (Yu, 2012). In this 'no play era', children were confined to narrow and crowded rooms and were offered little chance to play.

\section{0-2008: 'False Play' Era}

Children were encouraged to only play games mechanically according to the themes, steps and roles formulated by teachers. Ms. Cheng observed that the children's enjoyment could be described as 'false joy', in which they appeared devoid

\footnotetext{
${ }^{1}$ Anji educators insist that in the kindergartens of Anji, children lead their own play and selfexpression. Children chose what, where and with whom to play. According to the Anji teachers, self-determination in play, ownership of discovery and learning in play and the time and freedom to express complex intentions in play, is True Play.

${ }^{2}$ The official website of Anji play introduced the formation process of Anji Play in detail. The introduction of the three stages in this study are all taken from http://www.ajplaychina.com/Home/ Contents/detail.html?id=2939andkey=fazhanandkeywords=发展历程
} 
of the pleasures encountered in discovery play. Therefore, she referred to this as 'false play'.

\section{9-Present: 'True Play' Era}

Characterized by the words "Love, Risk, Joy, Engagement, Reflection”, Anji Play is synonymous with "True Play", in which children have autonomy in their playful activity. In such play, there is the potential to conduct in-depth, complex and lasting exploration in spontaneous and autonomous play. With the support of the local government, the reform of children's daily opportunities to include 'True play' is the practice of preschool education promoted by all kindergartens in the county.

On the basis of the True Play, developed over 9 years of reflective practice, Anji Play explores a set of Anji Play Curriculum which focus on children's play experience and cover various forms of activities in kindergartens. At the individual level, teachers voice that in previous eras, they felt deeply shackled by formalism and utilitarianism, tired yet inefficient, resulting in job burnout; thus, Cheng (2019) argues that the Anji approach not only allows children but also teachers to feel a sense of happiness. At the institutional level, Anji approach is a new mode that takes the reform of preschool education into the overall development plan of community and rural areas $(\mathrm{Li}, 2019)$. At the societal level, the documents issued by China have absorbed the Western early education ideas and specific practices that pay attention to the value of childhood. Although the Guidance for Kindergarten Education (trial version) issued in 1989 clearly points to 'Taking play as the basic activity, integrating education into various activities', ${ }^{3}$ what kind of play to implement and how to implement the play has been gradually explored over the years. Education in China emphasises the cultivation of collectivism and the adaptation of children to social norms and social organisational structure. Therefore, educational practice is shaped by cultural norms, control and discipline that focus on collective cultural responsibility. Anji Play, however, puts the preschool education ideological paradigm into practice by emphasising play as the 'basic activity'. Researchers such as Coffino and Bailey (2019) point out that the Anji Play approach 'is deeply resonant with Western models of experiential learning' (p. 4).

To a certain extent, Anji Play has absorbed Western democratic culture found in Nordic countries' approaches to early childhood. However, compared with the Nordic countries, Anji emphasizes the education in the play and pays attention to children's reflection and learning. Combined with the local natural conditions, redefinitions of the value of childhood and the rights of the child, Anji Play is a revolutionary model that has changed the kindergarten culture.

\footnotetext{
${ }^{3}$ Retrieved September April 1, 2020, from Ministry of Education, PRC, http://www.moe.gov.cn/ srcsite/A02/s5911/moe_621/201511/t20151119_220023.html
} 


\subsection{Cultural Relativism}

Norwegian scholar Birkeland (2016) criticized the inclination to evaluate educational practice from a mono-cultural perspective in cross-cultural comparative studies. Cultural relativity is an undeniable fact and cultural relativism holds that the outsiders should not use their own set of standards to measure the moral or social institutions of other culture (Donnelly, 1984).

Focusing on culture is the historical choice of Comparative Education (CE), which is also an important theme of contemporary CE study (Yang, 2017). After the 1970s, the qualitative research methods of comparative education quickly rose. Comparative education scholars uphold cultural relativism, emphasized the value of internal views, the importance of cultural models and the practice of education (L. R. Yang, 2015, S. P. Yang, 2012). We take cultural relativism as our theoretical framework aiming to go deep in different cultures to practice and experience, not just to describe the surface of the phenomenon. To explore children's cultural formations through outdoor play, we need to overcome our own cultural prejudice and be aware of bringing our own value orientation into the research process.

\subsection{Method}

The material presented in this chapter is from a comparative qualitative study in which an ethnographic approach was taken. Our research method was influenced by 'video-cued multi-vocal ethnography' used by Tobin et al. (2009). Tobin and his colleagues photographed the daily life of kindergartens in the three countries of the United States, China, and Japan, and edited the video into a 20 -min short film. The researchers invited early childhood educators from three countries to discuss the same video in order to trigger multi-party dialogues, explanations and arguments. Tobin et al. (2009) use conceptualizations of culture as the main tool to explain phenomena, pay attention to the interpretation of cultural insiders, and put the culture-based classifications and concepts above objectivity. These explanations and arguments may reveal the core concepts, goals and concerns of early childhood education in a culture.

Inspired by Tobin, we collected photo observations, anecdotal recording and interviews from one kindergarten in Bergen, Norway and one in Anji, China. The observation results focusing on outdoor play in the two kindergartens were discussed with kindergarten teachers, principals, professors and college students from China and Norway. Data were gathered in order to interpret the core concepts, goals and concerns of Norwegian and Anji play from multiple perspectives so that we could better understand children's cultural formation in the two cultural contexts. 
Table 6.1 Demographic information of the Anji kindergarten and Bergen kindergarten

\begin{tabular}{l|l|l}
\hline & Anji, China & Bergen, Norway \\
\hline Location & Anji & Bergen \\
\hline Outdoor area of kindergarten & 9100 square meters & 936 square meters \\
\hline Number of children & 554 & 20 \\
\hline Age of children & $3-6$ years old & $1-6$ years old \\
\hline Number of classes & 18 & 1 \\
\hline Number of employees & 65 & 5 \\
\hline
\end{tabular}

The data include 10 field observations, 40 photos, 15 transcribed interviews, 7 meeting minutes and 4 play sharing records ${ }^{4}$ of the Anji kindergarten.

The kindergarten in Anji is a garden-style, multi-functional kindergarten with diverse ecological environment. It is a model kindergarten for kindergartens in Zhejiang Province and an experimental base for education and scientific research of Anji Play. The kindergarten in Bergen is a small-sized, family-style kindergarten. The basic information of the two kindergartens is shown in Table 6.1.

The two kindergartens differ greatly in size, children's ages and the teacher-child ratio. The common feature and most important criterion for choosing these two kindergartens was the fact that both kindergartens value outdoor play, allowing opportunity for at least $2 \mathrm{~h}$ of outdoor play each day. However, each kindergarten also has specific characteristics that we attribute to institutional perspectives of children's outdoor play.

We refer to Hedegaard's (2009) model for analysis for interpreting the individualinstitutional-societal perspectives. Hedegaard proposed that children's learning and development through participation in institutionalised practice can be viewed from all three perspectives.

\subsection{Utilisation and Design of Kindergarten Outdoor Space from the Institutional Level}

\subsubsection{Challenge and Breakthrough: Kindergarten Return to Nature}

In the Anji kindergarten, children have at least $2 \mathrm{~h}$ of outdoor play every day. At about nine o'clock in the morning, the outdoor space comes alive with hundreds of children playing and talking with each other. Children climb up and down on the barrels, boards and large cubes, which they are able to stack as they wish; play with sand and water in the wide lawn, hillside and sand pool; and, paint on walls, ground, even one obsolete car.

\footnotetext{
${ }^{4}$ Play Sharing records is a fixed procedure of Anji, which will be described in detail in the following text.
} 
The terrain of the Anji kindergarten has been carefully and artificially designed; venues of different materials afford different types of activities, including lawn, sand, plastic floor, tile, marble and cobblestone. In addition to a variety of terrain type, Anji kindergarten also builds a variety of uneven ground, such as slopes, slideways, caves and gullies with a certain slope and height to provide the experience of tilt, conversion, inertia, friction and balance brought by different slopes.

Rich in variety and quantity, the Anji kindergarten provided low-structured, open-ended materials of all sizes, include both highly designed and found objects whose size and variety invite children to engage in large-scale construction, design, combination, recombination, revision, imagination and self-expression (Fig. 6.1). Anji educators believe that play materials are the material basis of children's play. Providing sufficient materials with various playing methods can meet children's needs and further enhance children's rights (Cheng, 2019). Based on different types of materials and equipment, the outdoor space is divided into climbing area, sand water area, construction area, swing area, rolling plastic barrel area, painting area and role-playing area. At present, each class play in one area for one month, then change to another area.

Water, sand and soil are also important resources for children's outdoor play and there are a variety of faucets. Children use water to play sand, draw, make canals, play mud and clean themselves after playing. They work together to connect pipes

a
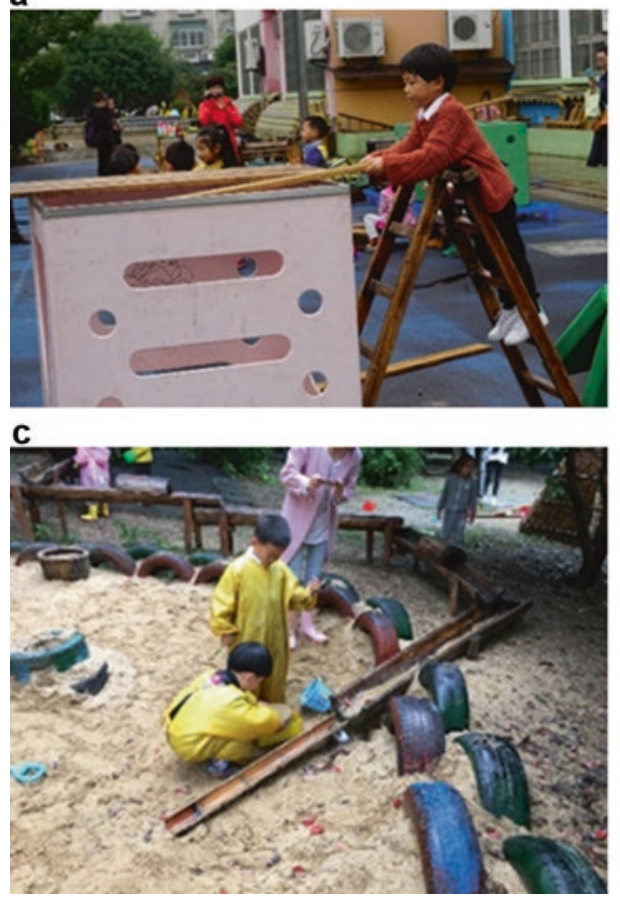

b

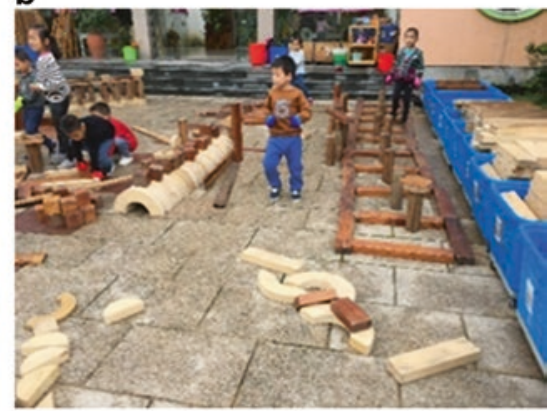

Fig. 6.1 Children challenge themselves by manipulating various materials. (Source: Author 2018) 
to transport water and dig sand to make canals which were big projects that appeared to endlessly fascinate the children.

Anji's educators have consciously shifted from the traditional knowledge-based and teacher-based orientations to the child-based orientation. Compared with the Chinese traditional, flat playground covered with large outdoor equipment, highlystructured toys and materials, Anji kindergarten matches the adult's educational intention with the children's needs. Through changing the environment, materials and time from the perspective of children, providing children with choices, Anji kindergarten presented a new play state and promotes teachers' continuous reflection and improvement.

\subsubsection{Inheritance and Continuation: Kindergarten in Nature}

At the Bergen kindergarten, after lunch, children will go outdoors for 2-3 h (except 'camping day' every Thursday when they are outdoors the whole day). Children sometimes play on the grounds of the kindergarten, and sometimes go off-site to nearby communities, forests, mountain, lakeside and other natural places. Due to the small number of children, children seemingly merged into the natural surroundings.

Norwegian teachers and experts believe that there is no need to provide so many materials. One of the professors of Western Norway University of Applied Sciences (HVL) pointed out that nature can provide rich materials and low-structural materials can stimulate children's imagination and creativity. As the principal said in interview: 'It's the forest that never gets empty.' Natural resources are the most important source of learning (Fig. 6.2).

Inside of kindergarten grounds, the playground consists of varied terrain with space to actively play. There are plum and apple trees in addition to berry bushes and children can climb and explore the environment, using all the possibilities. The ground of the Bergen kindergarten is an uneven and unmodified natural site and it adjusts according to local terrain conditions. The principal of the Bergen
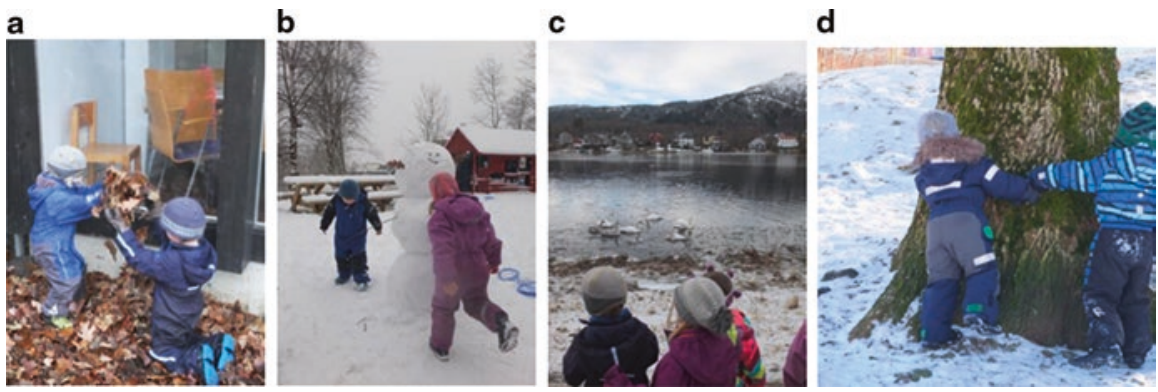

Fig. 6.2 Different kinds of natural elements in and out of the Bergen kindergarten. (Source: Author 2018) 
kindergarten stressed the importance of uneven and natural ground, which can help children conduct themselves to be able to keep balance without falling. She further pointed out that there are many mountains in Bergen, and children must learn how to deal with uneven mountain roads.

Teachers not only make full use of natural and neighborhood sources near the kindergarten, but also organize collective outdoor activities outside of the kindergarten, such as hiking the 7-Mountains (the seven mountains surrounding Bergen, Norwegian name: De 7 Fjell), visiting Langegården (a local farm in Bergen) every fall and spring and the skiing trip to Finse ${ }^{5}$ for 3 days in April.

We can clearly see that the Bergen kindergarten outdoor play focus on natural elements, and most of the children's outdoor activities interact with nature outside of the kindergarten. As the Framework Plan for Kindergarten of Norway (2017, p. 52) explicitly proposed that 'kindergartens shall enable the children to appreciate nature and have outdoor experiences that teach them to move around and spend time in the outdoors during the different seasons.' The Norwegian interviewees felt that the kindergarten was preparation for life outside the kindergarten and the outdoor life is education for sustainable development. By observing children's outdoor play, as researchers we felt that in Bergen, children are the children of nature, and human beings are the children of nature.

\subsubsection{Similarities and Differences of Kindergarten Outdoor Environment from the Institutional and Societal Levels}

The two kindergartens both reflect the growth of children in the outdoors. However, the Anji and Bergen kindergartens are quite different in terms of utilisation and design of kindergarten outdoor space. The Anji kindergarten provides a welldesigned outdoor space full of teachers' pedagogical input, while the Bergen kindergarten is more open and integrated with ecological and natural environment. Although both are urban, the Bergen children have better access to off-site areas with more diverse physical affordances and the Anji site has to re-create what is naturally available for the Norwegian children in a relatively enclosed space. In addition to population density of children and social security conditions, the differences of outdoor environment are largely influenced by cultural values of the institutional perspective.

Norwegians are strongly attached to nature (Borge, Nordhagen, \& Lie, 2003). Nature preschool has become popular in Scandinavian countries (Lysklett \& Berger, 2017). A nationwide parental survey show forests are the most common outdoor space in residential areas in Norway (Gundersen, Skar, O'Brien, Wold, \& Follo, 2016). In survey responses, $97 \%$ of parents stated that their children have access to

\footnotetext{
${ }^{5}$ Finse is an area in the Ulvik municipality of Hordaland, Norway. It is an ideal place for skiing and snowboarding and 2.5 hours by train from Bergen.
} 
forests within walking or cycling distance from home and when it comes to suitability for play, $88 \%$ state that their children, in general, have good or very good opportunities for play in nearby nature (Gundersen et al., 2016).

In China, the benefits of exploring nature for young children are being acknowledged and expressed in policy and practice in recent years. Guideline for Learning and Development of 3-6 Aged Children (Ministry of Education, 2012) suggests to 'take children into contact with nature to stimulate their curiosity and investigation desire (p. 43).' However, modern Chinese society attaches great importance to the development of cities. From the perspective of commercialisation, the kindergartens in rural areas are relatively belittled. Modern kindergartens tend to be urbanised and commercialised. Urbanisation has resulted in children in many cities being separated from contact with nature, despite the many benefits that this can provide for play and learning. Big gaps exist between needs and reality in natural playground planning and design (Wang, Woolley, Tang, Liu, \& Luo, 2018). Anji appropriated the state of urbanisation under the leadership of Cheng Xueqin in the process of China's urbanisation. Through her own investigation, learning and personal experience, Cheng strived to return children to nature and develop various abilities through activities in nature. Therefore, the cultural conditions for outdoor play in Anji Play settings attempt to replicate some of the variety of features that may be found when venturing off-site into more natural settings; yet, the resources that are provided are more in keeping with an urban landscape, e.g., made from plastic and recycled materials.

On the whole, the Bergen's kindergarten is a kindergarten in nature. Children's outdoor play in natural situations occur naturally without teachers' presupposition or requirements, while the Anji kindergarten's outdoor environment is still created by adults for children. Although the children are allowed some choice in how they use the materials provided, in China, teachers often hold a static and isolated view of educational environment subconsciously (Huang, Zhao, \& Jarrett, 2019). Kindergartens often take 'environment' as a separate topic for research and implementation. Through carefully designing the environment to meet children's various needs and development, the Anji teachers expect children to accept and practice their educational ideas and intentions, that is, problem-solving and deep learning.

\subsection{Learning and Reflection of Outdoor Play from the Individual Level}

Reflection of outdoor play is timetabled into the schedule for everyday activities in the Anji kindergarten. It is a semi-formal teaching opportunity organised by teacher and directed by children. There are three ways to reflect: (1) Reflection during play. (2) Recording Play Stories. (3) Play Sharing. Observation of a 6-year-old boy Playing Sharing in the Anji kindergarten illustrates how children are supported by teachers, peers and the environment to reflect and express their play experiences. 


\section{Extract from Observation of Zhangxiao (anonymized) Playing Sharing}

After playing with gyro toys in the construction area during outdoor play, the teacher organised the children to discuss and share with each other.

Zhangxiao: I feel that the lace-shaped gyro can beat your opponent away.

Teacher: Opponent? What are you playing today?

Zhangxiao: The Gyro Battle!

Teacher: The Gyro Battle, there are opponents, right? I have photographed it for you. Let's have a look (show the video). Is this?

Zhangxiao: Yes, that's it.

Teacher: Oh, this big one is an arena.

Zhangxiao: I have a question, why my nut arena always tilted?

Teacher: Can you help him to solve it?

Amy: The screws are loose.

Teacher: She feels that the screw is loose.

Zhangxiao: But everything is normal. The screws in it haven't loosened.

Teacher: He said that he checked every one of them. Maybe it was one of the reasons.

Who else knows why his arena is always tilted?

Luna: There must be someone who touches it very hard and it will tilt.

Teacher: What reason did Luna say just now?

Zhangxiao: She just said that someone must have touched it heavily, but we all touched it lightly, sometimes we didn't touch.

Teacher: Luna thinks that the reason why it collapsed might be that a very heavy external force touched it, and it just fell unbalanced, right? But no one touched it. What is the reason? Tom, what do you think?

Tom: It might be that the next thing is supported by only one foot.

The child, Zhangxiao's, perspective. Zhangxiao and several other boys played the game of "The Gyro Battle". During play, Zhang Xiao found that the nut arena they built always tilted. After returning to the classroom, Zhang Xiao record their play stories by drawing (Fig. 6.3) and can't wait to ask this question during Playing Sharing. Other children combine their own experience to help him analyze the cause of the problem. Around this issue, the children discussed in depth for about $20 \mathrm{~min}$, and many of them contributed their ideas. Finally, the teacher suggested that the children can test these conjectures through practical operation in the afternoon.

The Kindergarten Teacher's Perspective During outdoor play time, as a nonparticipant observer, the teacher is always observing children with using her mobile phone to take videos and photos. After returning to the classroom, she imports the videos and photos into the TV in the classroom to play relevant videos and photos in time for the whole class. When children share their play stories, the teacher can help them sort out, analyze and summarize their experiences, and slightly promote other children to actively think and participate in discussions.

The Pedagogue's Perspective Anji educators recognize that reflection about the experiences in plays has a critical role in translating experience to knowledge. Metacognitive reflection allow children and adults to gain deeper insight into the complexity of their thoughts, actions, learning and development, foster greater complexity and challenge in play. In the kindergarten in Bergen, discussion and reflection is not a fixed time procedure, but a random and informal sharing exchange. 


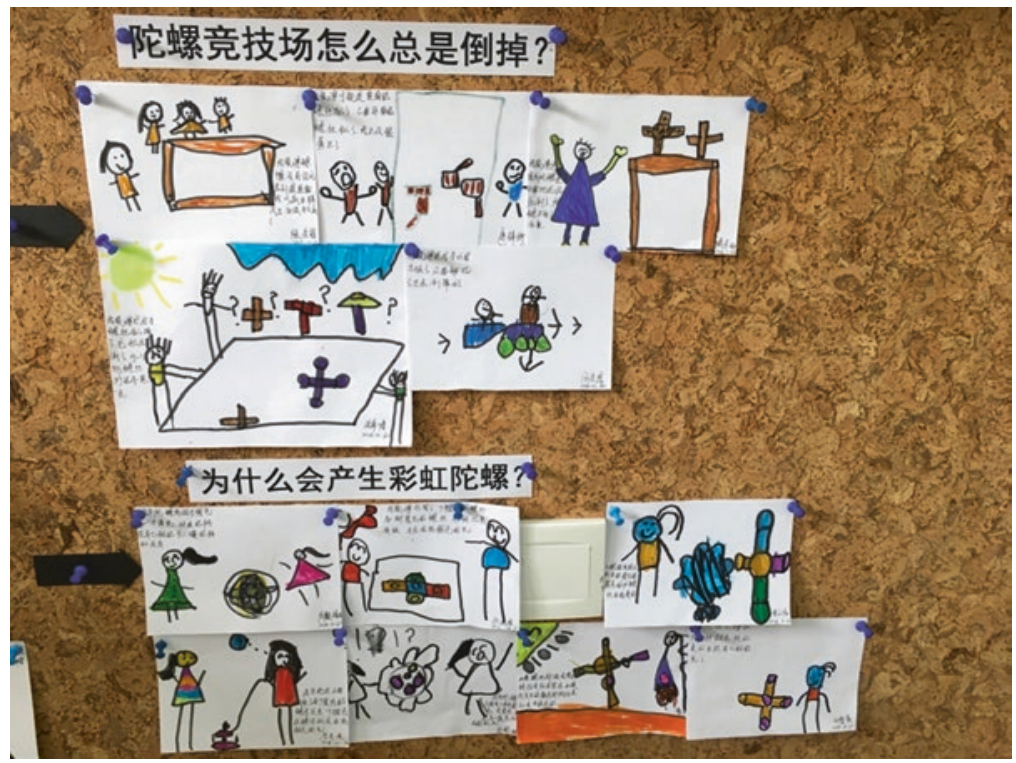

Fig. 6.3 Zhangxiao's play story of "Why is the nut arena always tilted?" (Source: Author 2018)

Norwegian teachers see no need to organise regular, collective discussions; the individual interests and motivations of children are more important, according to our interview findings. A Nordic professor questioned the content and form of the Playing Sharing activity,

\begin{abstract}
'Play contains multiple phenomena, children's experience in the play is quite complicated, may be contain multiple dimensions of society, emotion, creativity, and imagination. But the discussion in the classroom is relatively simple. After returning to the classroom, it is more like subject learning and cognitive discussion. There may be some children who are not very interested in the aspects that teachers often pay attention to, such as architecture or sandstone, which cannot be connected with their own experience' (interview, 29 October 2018).
\end{abstract}

Anji kindergarten teachers also point out this problem with traditional Chinese approaches to early childhood pedagogy at one staff-meeting (31 October, 2018). They are now consciously cultivating the ability of teachers to organise discussion and develop it into a comprehensive and cross-curricular discussion, including health, language, society, science and art.

However, from the child's perspective, it seems that Zhangxiao and the others enjoy the in-depth conversation that they shared with the teacher. The conversation lasted $20 \mathrm{~min}$ and the scientific concept development supported by the teacher planning the afternoon's activities to inquire further was in response to the children's interests. This demonstrates the value of the Anji Play approach, which builds upon children's discovery, a characteristic of True Play. 


\subsection{Significant Features of Cultural Formation from the Three Levels}

Through the comparison and analysis of Anji and Norwegian kindergartens, we trace different core concepts, goals and concerns relating to children's cultural formation in relationship to all the three levels.

The Children's Perspective Children in Anji kindergarten learn knowledge by solving a series of interesting and challenging practical problems. Through "learning by doing", children actually experience the operation process and find the content that they are interested in. The Play Sharing activities organized by teacher focus on solving practical problems to improve children's logical thinking and problem-solving ability. In Bergen, the symbolic meaning of construction is considered important. Children's activity is encouraged to be imaginative and creative, in order that even practical activities support holistic development.

The Institutional Perspective The Anji kindergarten emphasizes pragmatism and drawing out conceptual knowledge from play situations. By providing rich and diverse materials focusing on building, manipulating and movement, children learn to share, record, think and solve problems. The use of the play equipment that has been created on the kindergarten grounds provides some stimulus for further learning when indoors. In contrast, the Bergen kindergarten appeared to pay more attention to the immediate links between the kindergarten and the world beyond the kindergarten, specifically cultural and natural experiences based upon the built and natural landscape within which the kindergarten already sits. There was an emphasis on aesthetic qualities, such as melodious music, the spiritual world and the meaning that children give to the world around them.

The Societal Perspective Since the Opening of China, in 1987, Chinese society has gradually addressed issues concerning poverty and has begun to attach importance to vulnerable groups, especially children. The contemporary early childhood curriculum in China can be seen as reflecting a hybrid of three cultural threads, traditional culture, communist culture, and Western culture (Zhu \& Zhang, 2018). These three cultures are in some ways contrary to each other. For example, Western societies can be called individualistic societies: advocating competition and individual initiative, emphasizing the differences between people. Whereas the collectivist orientation has been deeply entrenched in Chinese culture for thousand years, which stresses the priority of group goals over individual goals and the importance of cohesion within social groups (Pan, Wang, \& Li, 2018.) This could be linked to those principles of AnjiPlay, which have adopted Western ideals of democracy and individual choices to demonstrate some of the conflicts.

Through the reform from 'False play' era to 'True play' era, AnjiPlay is challenging some of the social pressures for collectivism, yet retain elements that support children's development alongside the 'free play'. At the same time, the collective 
discussion of Play Sharing and cooperative construction in outdoor play also reflect collectivism that emphasises the interdependence of each individual. Therefore, AnjiPlay is a breakthrough improvement due to the changes of Chinese society, influenced by a hybrid of three cultural threads and reorientation of the value of childhood.

Nordic child centeredness and the Nordic welfare state are two cultural aspects of Nordic countries (Kristjansson, 2006). Among the Nordic countries, Norway is a typical modern welfare state. The Nordic welfare system gives adequate benefits for children and families. Combined with a high living standard and a view of nature as an arena for recreation and well-being, most people in the Nordic countries spend an extensive amount of their spare time outdoors (Sandseter \& Lysklett, 2018). Across generations, the tradition of visiting nature areas and hiking in the mountains or forest areas has been kept as a natural part of daily life (Borge et al., 2003). This cultural heritage is also integrated into the education system as part of the basis on which the content and practices of early childhood education and care (ECEC) institutions are formed. The kindergarten values equality, inclusiveness and the rights and status of children. Children are encouraged to experience the authenticity of the natural life during the free outdoor play, develop awe and love for nature and give meaning to the world through imaginary paths, dialogue with nature, and the use of nature materials as symbols and props in play.

\subsection{Conclusion}

In general, the findings demonstrated that kindergarten is set within the natural world in Norway and natural world is brought into the kindergarten in China. Also, the Norwegian kindergarten traditionally pays attention to what children already know, and the Chinese kindergarten tradition pays attention to what children do not yet know.

There are obvious differences between the two kindergartens on the terrain types, outdoor equipment, outdoor area and natural elements of outdoor space. Anji places emphasis on the design of outdoor space and children's skills using designed, recycled, rustic and local materials while the Bergen kindergarten pays attention to the utilisation of existing outdoor space, making full use of natural and neighborhood sources in and outside of the kindergarten.

Differences in outdoor space also lead to differences in children's outdoor play. In Anji, children's play varies according to different kinds of materials that teachers bring to the space. The Norwegian kindergarten's outdoor activities are seasonal and the children's activities vary according to different seasons based upon what they find. Children can fully experience and explore the change of the nature in the lake, forest, mountain, farm, etc.

Teachers of the two places also have different ideas on the outdoor learning mode. Teachers of Anji mainly observe when in the outdoors rather than directing or interfering with children's play. They attach great importance to the reflection and collective discussion after outdoor play and role model learning. Teachers in the Bergen kindergarten stress engaging with children during the play itself and value 
children's individuality and individualized learning. They do not necessarily bring the play scenarios back into the classroom for discussion and reflection.

The culture seems to shape how outdoor play is performed. Although, there are many differences between cultures in outdoor space and educational concepts, both of the outdoor spaces are interesting and different types of play can be created, which provide children with different levels of challenge and meet the development needs of children with different ages. Most of the outdoor play materials are lowstructured and have many affordances.

Finally, Bergen's kindergarten education is situated within consensus and promotion at the national level. Anji is only a partial breakthrough in a small area of China. It is not the universal education mode in China, but an influential, innovative play-based education on behalf of the direction of Chinese preschool education reform. We believe this work can be inspiring not only to China and Norway, but also for many other kindergarten teachers, stakeholders and researchers, wanting to improve the quality of the pedagogical practice in ECE to provide conditions for children's learning, development and cultural formation.

Acknowledgements We acknowledge support from Norwegian Agency for International Cooperation and Quality Enhancement in Higher Education (Diku), The UTFORSK Programme hosted by Åsta Birkeland, Western Norway University of Applied Sciences, Kindergarten Knowledge Centre for Systemic Research on Diversity and Sustainable Futures (KINDknow), and the involved kindergartens in Norway and China.

\section{References}

Acar, H. (2014). Learning environments for children in outdoor spaces. Procedia - Social and Behavioral Sciences, 141, 846-853.

Bento, G., \& Dias, G. (2017). The importance of outdoor play for young children's healthy development. Porto Biomedical Journal, 2(5), 157-160.

Birkeland, A. (2016). Cross cultural comparative education - Fortifying preconceptions or transformation of knowledge? Policy Futures in Education, 14(1), 77-91.

Borge, A. I. H., Nordhagen, R., \& Lie, K. K. (2003). Children in the environment: Forest day-care centers. The History of the Family, 8(4), 605-618. https://doi.org/10.1016/j.hisfam.2003.04.001

Cheng, X. Q. (2019). Play, hands down and discover the child. Shanghai: East China Normal University Press.

Coffino, J. R., \& Bailey, C. (2019). The Anji play ecology of early learning. Childhood Education, 95(1), 3-9.

Donnelly, J. (1984). Cultural relativism and universal human rights. Human Rights Quarterly, 6(4), 400-419.

Gundersen, V., Skar, M., O’Brien, L., Wold, L. C., \& Follo, G. (2016). Children and nearby nature: A nationwide parental survey from Norway. Urban Forestry and Urban Greening, 17, 116-125.

Hedegaard, M. (2009). Children's development from a cultural-historical approach: Children's activity in everyday local settings as foundation for their development. Mind, Culture, and Activity, 16(1), 64-82.

Huang, J., Zhao, Y. L., \& Olga, S. J. (2019). A comparative study on the game space between Chinese and American kindergartens. International and Comparative Education, 01, 92-99.

Kristjansson, B. (2006). The making of Nordic Childhooods. In J. Einarsdottir \& J. T. Wagner (Eds.), Nordic childhoods and early education. Philosophy, research, policy and practice in Denmark, Finland, Iceland, Norway and Sweden (pp. 13-17). Greenwich, CT: Information Age Publishing.

Li, J. M. (2019). Learning from Anji and deepening reform. Preschool Education, 06, 10-13.

Lysklett, O. B., \& Berger, H. W. (2017). What are the characteristics of nature preschools in Norway, and how do they organize their daily activities? Journal of Adventure Education and Outdoor Learning, 17(2), 1-13. 
Maynard, T., \& Waters, J. (2007). Learning in the outdoor environment: A missed opportunity? Early Years and International Journal of Research and Development, 27(3), 255-265.

Ministry of Education (MOE). (2012). Guideline for learning and development of 3-6 aged children [3-6岁儿童学习与发展指南]. Beijing, China: Capital Normal University Press.

Mohidin, H. H. B., Ismail, A. S., \& Ramli, H. B. (2015). Effectiveness of kindergarten design in Malaysia. Procedia - Social and Behavioral Sciences, 202, 47-57.

Moser, T., \& Martinsen, M. T. (2010). The outdoor environment in Norwegian kindergartens as pedagogical space for toddlers' play, learning and development. European Early Childhood Education Research Journal, 18(4), 457-471. https://doi.org/10.1080/1350293X.2010.525931

Norwegian Directorate for Education and Training. (2017). Framework plan for Kindergartens. Retrieved May 15, 2019, from https://www.udir.no/rammeplan

Pan, Y., Wang, X., \& Li, L. (2018). Early childhood education and development in China. In International handbook of early childhood education (pp. 599-622). Dordrecht, The Netherlands: Springer.

Salı, G., Akyol, A. K., \& Baran, G. (2014). An analysis of pre-school children's perception of schoolyard through their drawings. Procedia - Social and Behavioral Sciences, 116, $2105-2114$.

Sandseter, E. B. H., \& Lysklett, O. B. (2018). Outdoor education in the Nordic region. In International handbook of early childhood education (pp. 889-906). Dordrecht, The Netherlands: Springer.

Tobin, J., Hsueh, Y., \& Karasawa, M. (2009). Preschool in three cultures revisited: China, Japan, and the United States. Chicago, Ill: The University of Chicago Press.

Wagner, J. T., \& Einarsdottir, J. (2006). Nordic ideals as reflected in Nordic childhoods and early education. In J. Einarsdottir \& J. T. Wagner (Eds.), Nordic childhoods and early education. Philosophy, research, policy and practice in Denmark, Finland, Iceland, Norway and Sweden (pp. 13-17). Greenwich, CT: Information Age Publishing.

Wang, X., Woolley, H., Tang, Y., Liu, H. Y., \& Luo, Y. (2018). Young children's and adults' perceptions of natural play spaces: A case study of Chengdu, Southwestern China. Cities, 72, 173-180.

Yang, L. R. (2015). A probe into methodological transformation of comparative education research from the perspective of post-structuralism, Ph.D. thesis. Changchun, China: Northeast Normal University.

Yang, M. Q. (2017). Cultural-based inquiry paradigm and its application in comparative education. Educational Research, 38(01), 23-29.

Yang, S. P. (2012). A study on the paradigm of comparative education, Ph.D. thesis. Chongqing, China: Xinan University.

Yu, Y. P. (2012). Find the root of "primary school" of kindergarten education. Liaoning Education, $18,24-25$.

Zhu, J., \& Zhang, J. (2018). Review and reflection on the curriculum reform of early childhood education in China. In International handbook of early childhood education (pp. 1173-1189). Dordrecht, The Netherlands: Springer.

Open Access This chapter is licensed under the terms of the Creative Commons Attribution 4.0 International License (http://creativecommons.org/licenses/by/4.0/), which permits use, sharing, adaptation, distribution and reproduction in any medium or format, as long as you give appropriate credit to the original author(s) and the source, provide a link to the Creative Commons license and indicate if changes were made.

The images or other third party material in this chapter are included in the chapter's Creative Commons license, unless indicated otherwise in a credit line to the material. If material is not included in the chapter's Creative Commons license and your intended use is not permitted by statutory regulation or exceeds the permitted use, you will need to obtain permission directly from the copyright holder. 